\title{
ChemComm
}

\section{Efficient catalyst removal and recycling in copolymerization of epoxides with carbon dioxide via simple liquid-liquid phase separation $\dagger$} \author{
49, 9332 \\ Received 24th July 2013,
}

Cite this: Chem. Commun., 2013, Accepted 15th August 2013

DOI: $10.1039 / c 3 c c 45622 f$

www.rsc.org/chemcomm

A simple and efficient catalyst removal system has been developed in the cobalt-salen-catalyzed copolymerization of propylene oxide with carbon dioxide. The present system requires no prior modification of the catalyst, and the removal is achieved by simple addition of myristic acid, followed by organic liquid-liquid phase separation.

The alternating copolymerization of epoxides with carbon dioxide to give aliphatic polycarbonates, pioneered by Inoue and coworkers in the $1960 \mathrm{~s},{ }^{1}$ has attracted much attention as one of the most promising processes for $\mathrm{CO}_{2}$ utilization. ${ }^{2}$ In the last decade, a variety of catalyst systems based on metal-salen complexes have been developed, ${ }^{2 c, 3-5}$ many of which show much higher catalytic activities than other conventional systems. Unfortunately, however, because metal-salen complexes are highly coloured, even a small amount of residual metal-salen complexes in the product polycarbonates leads to undesired coloration of these inherently colourless copolymers. In addition, highly active catalyst systems usually employ cobalt ${ }^{4,6}$ or chromium ${ }^{5,7}$ complexes, and contamination of these metals in the product polycarbonates could also be problematic due to their toxicity. It is therefore highly desirable to develop a method that allows for easy and efficient removal of these metal complexes from the polymers in this alternating copolymerization.

The conventional and most typical method for purification of the polycarbonates from metal catalysts is achieved by precipitation of polycarbonates with methanol, but repeated precipitation is required to obtain pure polycarbonates. To overcome this cumbersome purification procedure, several catalyst systems have been designed for easy separation of the metal catalysts.

\footnotetext{
${ }^{a}$ Department of Organic and Polymer Materials Chemistry,

Tokyo University of Agriculture and Technology, 2-24-16 Naka-cho, Koganei, Tokyo 184-8588, Japan. Tel: +81-42-388-7162

${ }^{b}$ Department of Chemistry and Biotechnology, Graduate School of Engineering, The University of Tokyo, 7-3-1 Hongo, Bunkyo-ku, Tokyo 113-8656, Japan. E-mail: nozaki@chembio.t.u-tokyo.ac.jp; Fax: +81-3-5841-7263; Tel: +81-3-5841-7261

$\dagger$ Electronic supplementary information (ESI) available: Detailed experimental procedures. See DOI: $10.1039 / \mathrm{c} 3 \mathrm{cc} 45622 \mathrm{f}$
}

For example, insoluble polymer-supported chromium/porphyrin ${ }^{8}$ and zinc/diiminate ${ }^{9}$ catalysts were employed in the copolymerization of cyclohexene oxide ( $\mathrm{CHO}$ ) with $\mathrm{CO}_{2}$, and these catalysts could be removed by filtration after the polymerization reaction. In addition to these catalyst immobilization approaches, modification of homogeneous metal catalysts has also been explored. Lee and coworkers reported a highly active cobalt-salen complex bearing four quaternary ammonium salt units for copolymerization of propylene oxide (PO) with $\mathrm{CO}_{2} \cdot{ }^{4 j}$ The product polymers could be purified by passing through a pad of silica gel, and the catalyst remaining on the silica gel could also be recovered and reused after sequential anion exchange processes. Darensbourg, Bergbreiter, and coworkers introduced a chromium-salen complex having polyisobutylene tethers for coplolymerization of $\mathrm{CHO}$ with $\mathrm{CO}_{2}{ }^{5}{ }^{d}$ In this system, due to the highly non-polar nature of the polyisobutylene tethers, the chromium-salen complex could be efficiently removed from the polycarbonates through $\mathrm{HCl}$ treatment in MeCN followed by extraction with heptane, and the recovered catalyst could also be reused for the copolymerization.

Although significant progress has been made for efficient catalyst removal as mentioned above, the major drawback for both immobilized and homogeneous methods is the requirement of design and synthesis of elaborate metal-ligand complexes. In addition, due to the modification of the catalyst, the polymerization activity can sometimes become lower than those of the corresponding parent metal complexes. To address this issue, Jessop and coworkers demonstrated an efficient purification of poly(cyclohexene carbonate) from a simple chromium-salen catalyst by way of switching the polarity of the amine solvent through introduction of $\mathrm{CO}_{2} \cdot{ }^{5 f}$

In this context, herein we describe the development of a simple catalyst removal system via liquid-liquid phase separation in the copolymerization of $\mathrm{PO}$ with $\mathrm{CO}_{2}$. The present system employs a readily available, standard cobalt-salen complex with no prior modification, and the separation is achieved by simple addition of a commercially available, long-chain alkylcarboxylic acid after the copolymerization reaction.

A schematic view of the catalyst separation system in our present study is illustrated in Fig. 1. The copolymerization of 


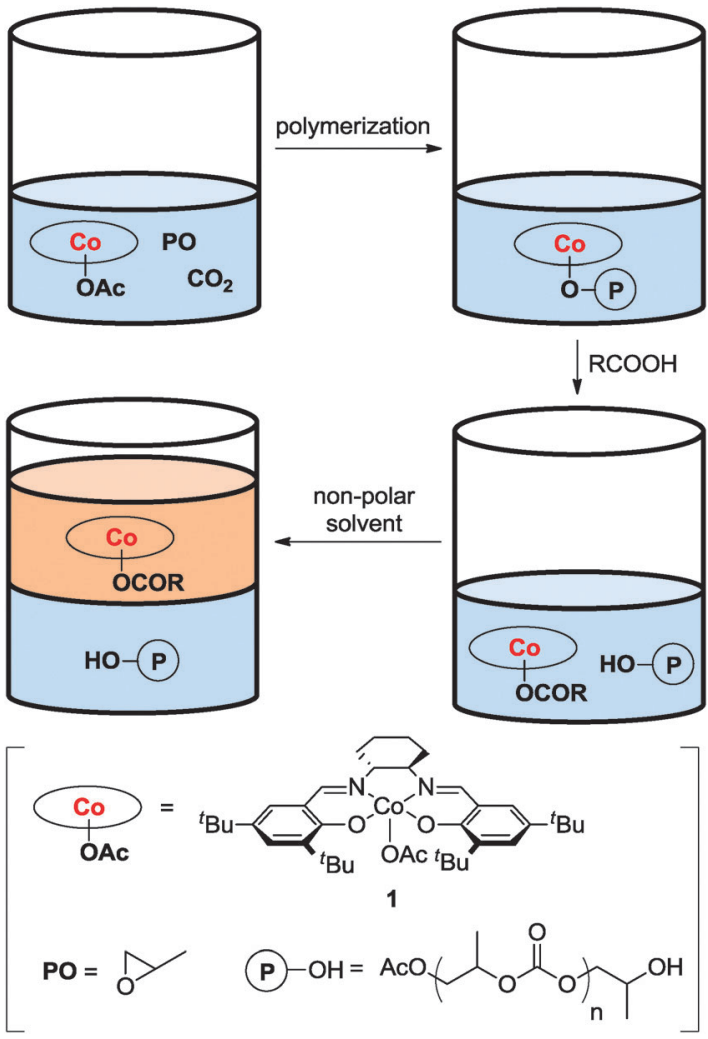

Fig. 1 Schematic representation of the catalyst separation in the copolymerization of propylene oxide with $\mathrm{CO}_{2}$.

PO with $\mathrm{CO}_{2}$ is conducted with readily available cobalt-salen complex $\mathbf{1}^{4 a, b, 10}$ as the catalyst in the presence of bis(triphenylphosphine)iminium chloride $([\mathrm{PPN}] \mathrm{Cl})$, and the reaction mixture is treated with a long-chain alkylcarboxylic acid $(\mathrm{RCOOH})$ after the copolymerization. The anionic propagated polymer chain on the cobalt centre is replaced by the carboxylate and released as neutral poly(propylene carbonate) (PPC). Because of the long-chain alkyl carboxylate on cobalt, the resulting cobaltsalen complex becomes highly soluble in non-polar hydrocarbon solvents, while the product PPC stays selectively soluble in polar solvents such as MeCN and DMF. Accordingly, the cobalt-salen complex can be easily separated from the product PPC via simple liquid-liquid phase separation by using immiscible non-polar and polar organic solvents.

In an initial investigation, we evaluated the efficiency of the catalyst separation by changing the chain length of the carboxylic acid after the copolymerization of $\mathrm{PO}$ with $\mathrm{CO}_{2}$. The copolymerization was carried out by using cobalt-salen complex 1 in the presence of $[\mathrm{PPN}] \mathrm{Cl}\left(\mathrm{PO} / \mathbf{1} /[\mathrm{PPN}] \mathrm{Cl}=4000 / 1 / 0.5,2.0 \mathrm{MPa}\right.$ of $\left.\mathrm{CO}_{2}\right)$. After the unreacted $\mathrm{PO}$ and $\mathrm{CO}_{2}$ were removed, the polymerization mixture was dissolved in $\mathrm{CH}_{2} \mathrm{Cl}_{2}$ and treated with a carboxylic acid (2 equiv. to 1 ). After removal of the solvent, the residue was dissolved in $\mathrm{CH}_{3} \mathrm{CN}$ and the cobalt-salen complex was extracted with hexane. As a starting point, acetic acid $\left(\mathrm{R}=\mathrm{CH}_{3}\right)$ was used and the amount of extracted cobalt-salen complex by this method was estimated to be $74 \%$ based on UV-VIS spectroscopy $\left(\lambda_{\max }=411 \mathrm{~nm}, \varepsilon=6.67 \times 10^{3} \mathrm{M}^{-1} \mathrm{~cm}^{-1}\right)$ (Table 1 , entry 1$)$. As expected, the use of longer alkylcarboxylic acids led to higher
Table 1 Effect of carboxylic acid for the efficiency of the catalyst separation

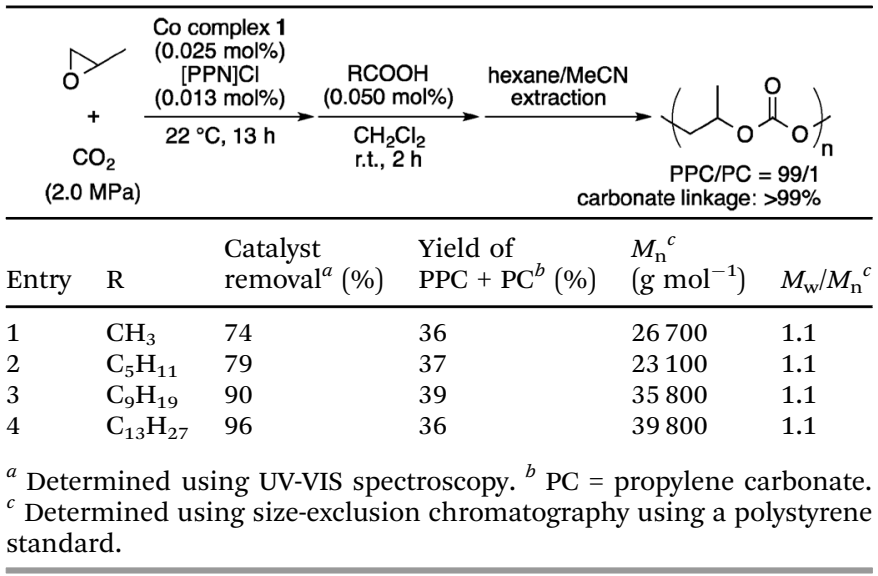

efficiency of the catalyst separation. Thus, $79 \%$ of the cobalt complex was removed by using caproic acid $\left(\mathrm{R}=\mathrm{C}_{5} \mathrm{H}_{11}\right.$; entry 2$)$, and the use of capric acid $\left(\mathrm{R}=\mathrm{C}_{9} \mathrm{H}_{19}\right)$ led to $90 \%$ removal under the same conditions (entry 3). Finally, as high as $96 \%$ of the cobalt-salen complex was extracted into the hexane phase by using myristic acid $\left(\mathrm{R}=\mathrm{C}_{13} \mathrm{H}_{27}\right)$ (entry 4). In this experiment, isolated PPC from the MeCN phase was also analyzed by ICP, and the amount of cobalt remaining in the polymer was found to be $15.6 \mathrm{ppm}$, which corresponded to $3.9 \%$ of the initially loaded cobalt-salen complex 1 (eqn (1)). It is worth noting that further purification of the polymer by repeating the same separation method once again gave the PPC with $1.9 \mathrm{ppm}$ cobalt, showing that $>99.5 \%$ of the cobalt could be removed by employing two cycles of this sequence. In comparison, ICP analysis was also carried out for the PPC obtained by the conventional precipitation method after the copolymerization reaction (eqn (2)). As much as 108 ppm of cobalt remained in the polymer after a single precipitation process, indicating that only $74 \%$ of the cobalt complex could be removed. $65.0 \mathrm{ppm}$ of cobalt ( $16 \%$ of the used cobalt) was still detected even after the second precipitation, clearly demonstrating the superiority of our present purification method.
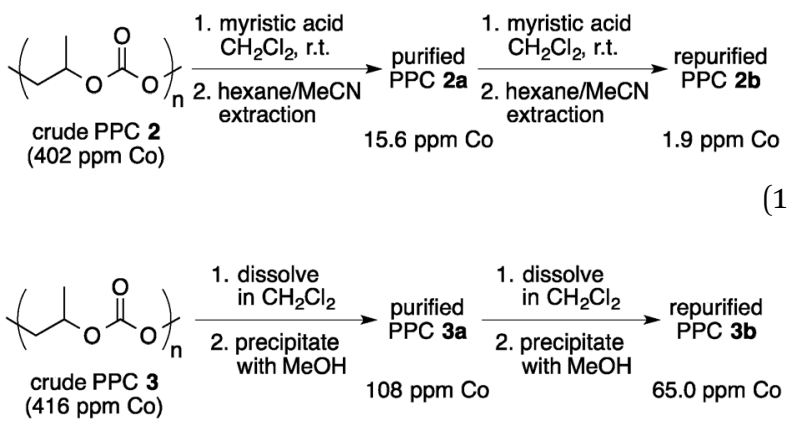

Having established an easy and efficient process for the catalyst removal in the present copolymerization, we turned our attention to recycling of the catalyst. Because the extracted cobalt-salen complex in the hexane phase is supposed to bear a carboxylate ligand (myristate instead of acetate), it should be ready to be used as the copolymerization catalyst after evaporation of the solvent. Indeed, the recovered catalyst displayed a 
Table 2 Recycling experiments for the cobalt-salen-catalyzed copolymerization of $\mathrm{PO}$ with $\mathrm{CO}_{2}$

\begin{tabular}{|c|c|c|c|c|c|c|c|}
\hline \multirow[b]{2}{*}{ Cycle } & \multicolumn{2}{|c|}{$+\begin{array}{c}\mathrm{CO}_{2} \\
(2.0 \mathrm{MPa})\end{array}$} & $\begin{array}{l}\text { complex } 1 \text { (cycle 1) } \\
\text { or } \\
\text { overed complex (cycles } 2-6) \\
(0.025 \text { mol\%) } \\
\text { [PPN]Cl }(0.013 \mathrm{~mol} \%)\end{array}$ & $\begin{array}{c}\begin{array}{c}\text { myristic acid } \\
(0.050 \mathrm{~mol} \%)\end{array} \\
\begin{array}{c}\mathrm{CH}_{2} \mathrm{Cl}_{2} \\
\text { r.t., } 2 \mathrm{~h}\end{array}\end{array}$ & \multirow{2}{*}{$\begin{array}{c}\begin{array}{c}\text { Co/salen } \\
\text { complex } \\
\text { (hexane phase) }\end{array} \\
M_{\mathrm{n}}{ }^{b}\left(\mathrm{~g} \mathrm{~mol}{ }^{-1}\right)\end{array}$} & \multicolumn{2}{|c|}{$\underbrace{\stackrel{O}{⿲ ㇒}}_{\text {(MeCN phase) }}$} \\
\hline & Yield of PPC + PC (\%) & $\mathrm{PPC} / \mathrm{PC}^{a}$ & TOF for PPC $\left(\mathrm{h}^{-1}\right)$ & Carbonate linkage $^{a}(\%)$ & & $M_{\mathrm{w}} / M_{\mathrm{n}}{ }^{b}$ & Catalyst recovery $^{c}(\%)$ \\
\hline 1 & 36 & $99 / 1$ & 111 & $>99$ & 39800 & 1.1 & 96 \\
\hline 2 & 29 & $99 / 1$ & 89 & $>99$ & 28200 & 1.1 & 94 \\
\hline 3 & 27 & $98 / 2$ & 80 & $>99$ & 22700 & 1.1 & 94 \\
\hline 4 & 28 & $99 / 1$ & 84 & $>99$ & 22400 & 1.1 & 96 \\
\hline 5 & 27 & $98 / 2$ & 82 & $>99$ & 23900 & 1.1 & 94 \\
\hline 6 & 23 & $96 / 4$ & 69 & $>99$ & 20500 & 1.1 & 91 \\
\hline
\end{tabular}

${ }^{a}$ Determined using ${ }^{1} \mathrm{H}$ NMR. ${ }^{b}$ Determined using size-exclusion chromatography using a polystyrene standard. ${ }^{c}$ Determined using UV-VIS spectroscopy.

reasonable activity for the copolymerization of $\mathrm{PO}$ with $\mathrm{CO}_{2}$ without further purification and the results of the recycling experiments of up to 5 times are summarized in Table 2. It is worth noting that the efficiency of catalyst removal (recovery) stays high for each cycle of the copolymerization (91-96\%), although the catalyst activity gradually decreases.

In summary, we have developed a simple and efficient catalyst removal system in the cobalt-salen-catalyzed alternating copolymerization of propylene oxide with carbon dioxide. The present system requires no prior modification of the cobalt-salen complex, and the catalyst removal is achieved by simple addition of a longchain alkylcarboxylic acid after the copolymerization, followed by organic liquid-liquid phase separation. The removal efficiency is much higher than the conventional purification method by precipitation, and the recovered cobalt catalyst can also be directly reused multiple times.

Support has been provided in part by the Funding Program for Next Generation World-Leading Researchers, Green Innovation and the Global COE Program "Chemistry Innovation through Cooperation of Science and Engineering”, from MEXT, Japan.

\section{Notes and references}

1 S. Inoue, H. Koinuma and T. Tsuruta, J. Polym. Sci., Part B: Polym. Lett., 1969, 7, 287.

2 (a) G. W. Coates and D. R. Moore, Angew. Chem., Int. Ed., 2004, 43, 6618; (b) H. Sugimoto and S. Inoue, J. Polym. Sci., Part A: Polym. Chem., 2004, 42, 5561; (c) D. J. Darensbourg, Chem. Rev., 2007, 107, 2388; (d) G. A. Luinstra, Polym. Rev., 2008, 48, 192.

3 H. Sugimoto, H. Ohtsuka and S. Inoue, J. Polym. Sci., Part A: Polym. Chem., 2005, 43, 4172.
4 (a) Z. Qin, C. M. Thomas, S. Lee and G. W. Coates, Angew. Chem., Int. Ed., 2003, 42, 5484; (b) C. T. Cohen, T. Chu and G. W. Coates, J. Am. Chem. Soc., 2005, 127, 10869; (c) X.-B. Lu and Y. Wang, Angew. Chem., Int. Ed., 2004, 43, 3574; (d) X.-B. Lu, L. Shi, Y.-M. Wang, R. Zhang, Y.-J. Zhang, X.-J. Peng, Z.-C. Zhang and B. Li, J. Am. Chem. Soc., 2006, 128, 1664; (e) W.-M. Ren, Z.-W. Liu, Y.-Q. Wen, R. Zhang and X.-B. Lu, J. Am. Chem. Soc., 2009, 131, 11509; $(f)$ R. L. Paddock and S. T. Nguyen, Macromolecules, 2005, 38, 6251; $(g)$ K. Nakano, T. Kamada and K. Nozaki, Angew. Chem., Int. Ed., 2006, 45, 7274; (h) K. Nakano, S. Hashimoto and K. Nozaki, Chem. Sci., 2010, 1, 369; (i) E. K. Noh, S. J. Na, S. S, S.-W. Kim and B. Y. Lee, J. Am. Chem. Soc., 2007, 129, 8082; $(j)$ S. S, J. K. Min, J. E. Seong, S. J. Na and B. Y. Lee, Angew. Chem., Int. Ed., 2008, 47, 7306.

5 (a) D. J. Darensbourg and J. C. Yarbrough, J. Am. Chem. Soc., 2002, 124, 6335; (b) D. J. Darensbourg, R. M. Mackiewicz, J. L. Rodgers, C. C. Fang, D. R. Billodeaux and J. H. Reivenspies, Inorg. Chem., 2004, 43, 6024; (c) D. J. Darensbourg and R. M. Mackiewicz, J. Am. Chem. Soc., 2005, 127, 14026; (d) C. Hongfa, J. Tian, J. Andreatta, D. J. Darensbourg and D. E. Bergbreiter, Chem. Commun., 2008, 975; (e) R. Eberhardt, M. Allmendinger and B. Rieger, Macromol. Rapid Commun., 2003, 24, 194; $(f)$ L. Phan, J. R. Andreatta, L. K. Horvey, C. F. Edie, A.-L. Luco, A. Mirchandani, D. J. Darensbourg and P. G. Jessop, J. Org. Chem., 2008, 73, 127.

6 (a) H. Sugimoto and K. Kuroda, Macromolecules, 2008, 41, 312; (b) A. Okada, S. Kikuchi, K. Nakano, K. Nishioka, K. Nozaki and T. Yamada, Chem. Lett., 2010, 1066.

7 (a) S. Mang, A. I. Cooper, M. E. Colclough, N. Chauhan and A. B. Holmes, Macromolecules, 2000, 33, 303; (b) D. J. Darensbourg and S. B. Fitch, Inorg. Chem., 2007, 46, 5474; (c) B. Li, G.-P. Wu, W.-M. Ren, Y.-M. Wang, D.-Y. Rao and X.-B. Lu, J. Polym. Sci., Part A: Polym. Chem., 2008, 46, 6102; (d) K. Nakano, M. Nakamura and K. Nozaki, Macromolecules, 2009, 42, 6972.

8 L. M. Stamp, S. A. Mang, A. B. Holmes, K. A. Knights, Y. R. de Miguel and I. F. McConvey, Chem. Commun., 2001, 2502.

9 K. Yu and C. W. Jones, Organometallics, 2003, 22, 2571.

10 M. Tokunaga, J. F. Larrow, F. Kakiuchi and E. N. Jacobsen, Science, 1997, 277, 936. 